\title{
THE E-PATIENT
}

\section{Ljubomir S. Kovachev \\ Pencho T. Tonchev ${ }^{1}$ \\ Kiril L. Nedialkov ${ }^{1}$}

Former Head of Department of

Propaedeutics of Surgical Diseases

(retired),

Medical University - Pleven,

Bulgaria

${ }^{1}$ Department of Propedeutics of Surgical

Diseases,

Medical University - Pleven, Bulgaria

\section{Corresponding Author:}

Pencho T. Tonchev

Department of Propedeutics of Surgical

Diseases,

Medical University - Pleven

1, St. Kl. Ohridski Str.

Pleven, 5800

Bulgaria

e-mail:ptonchev@gmail.com

Received: June 23, 2017

Revision received: August 21, 2017

Accepted: February 27, 2018

\section{Summary}

Advanced information technologies have entered all spheres of human activities. In healthcare, this happens much too fast and encompasses all its branches. How does the Internet form the relationship between patients and medical staff? What information do patients seek and how do they get it? What problems arise during the communication process via new means? How can we describe an e-patient? How does the Internet model the doctor-patient relationship in case of cancer, one of the most dramatic diseases? Are students prepared to face an e-patient and how are they trained to do it? What is to be done to optimize internet communication between patients and health providers? This review analyzes information on these issues and outlines some opportunities for solving problems arising against the background of IT use in health care.

Key words: e-patient; e-health; e-medicine

\section{Introduction}

One meta-analysis of global surveys of September 2002 found that there were 606 million Internet users on the worldwide network [1]. Until recently, the largest group of online users was in North America, but this has changed since 2003. The most substantial number is that in Europe (191 million), followed by the Asia-Pacific region (187 million) and North America (183 million), Latin America (33 million), Africa (6 million) and the Middle East (5 million). These figures reflect both the numbers of users and distribution of the Internet [2].

"Online doctor" was introduced as a term in the 2000 s, and is used by both the media and academic circles. It describes the generation of medics and healthcare practitioners who provide health services, including prescriptions for medicines on the internet [3]. An "e-patient" is a healthcare user who is fully involved in providing medical assistance. Electronic patients are considered as equal partners with their doctors in the healthcare process. Electronic patients collect information about medical conditions that affect them and their families using the Internet and other digital tools [4], and "e-medicine" is an online clinical medical facility created in 1996 by Scott Plants 
and Richard Laveli [5].

Medicine has been drastically changed by the Internet, which facilitates rapid dissemination of a considerable amount of information and immediate exchange of ideas. The Internet has become a source of medical information for nearly 98 million people in the United States [6]. For many people in most developed countries, the Internet is a powerful and familiar tool for health advice [7].

\section{The e-Patient}

The term "e-patient", meaning a patient who is equipped, active, empowered and committed to his health and healing, was created by Ferguson et al. (2007) [8]. E-patients get their information from a wide range of sources. They can use conventional search engines, find information from online support groups, and many of them have access to online journals through traditional libraries. Those who do not have legitimate access to articles in the journals use sites to share access to reports and databases to obtain the necessary information $[9,10]$.

For doctors, the Internet has increased the efficiency of patient care and has allowed collaboration between geographically scattered researchers [11]. The Internet has changed patient-doctor relationships by enabling patients to get information. Since doctors are no longer the primary sources of medical information, shared decision-making becomes a hallmark of the doctor-patient relationship. Although patients already have much more medical information, insight and introduction by doctors are essential to ensure an accurate understanding of the data collected from the Internet [2]. This issue has added dynamics to the doctor-patient relationship, and will fundamentally change the traditional office visit.

Furthermore, such visits could safely be replaced by exchanging information on the Web, including correcting and prescribing drug treatment for chronically ill patients. Such practices will reduce contacts in the waiting room between patients of different age groups. Because of the increasing flu epidemics, this will reduce the rate of a specific group of diseases accompanied by complications and exacerbation of chronic diseases. A superficial calculation immediately indicates some healthcare costs could be reduced.

We now know that women are more active seekers of health information than men [12, 13]. Younger individuals, on the other hand, are more active Internet users [14-17]. It is desirable that this proportion should change.

\section{The impact of Internet on cancer outcomes}

Malignant diseases present another severe problem, consuming tremendous resources and requiring psychological intervention. In developed countries, about $39 \%$ of cancer patients are Internet users, and approximately 2.3 million of them are worldwide online users. Another $15-20 \%$ of cancer patients are indirect Internet users, through members of their families or friends [2].

The First International Conference on Cancer and the Internet, organized by the European Oncology School and held in New York, had the subtitle "What is the Internet Impact on Cancer Outcomes?" A recent article in the American Cancer Society journal put a similar question [18]. Twenty-four studies covered 8697 cancer patients, $39 \%$ of them being Internet users [2]. Interestingly, this figure correlates with the oncologists' estimates: $30 \%$ of their patients used the Internet [19].

Socio-economic indicators of access to the Internet or lack of such are well known, i.e., the factors contributing to the "digital divide" are also present in cancer patients [20, 21]. Metz et al. (2003) and Smith et al. (2003) have found considerable differences in Internet use among cancer patients in university hospitals (48\%) and those treated in government hospitals (8\%). These differences are due to the socio-economic status of patients admitted to these two types of hospitals [22, 23].

Some studies rank the Internet second after healthcare professionals as the most important source of information on malignancies [24,25]. However, it may not be so important when it comes to making responsible decisions about cancer treatment. When asked which factor is most important for influencing their decisions to undergo therapy, men with prostate cancer say that doctors' recommendations (51\%), advice from friends and family (19\%), and information from books and journals (18\%) are the most 
important. Internet sources were quoted by $7 \%$ [26]. Raupach et Hiller (2002) reported that patients with breast cancer were particularly pleased with Internet information (89\%), and a smaller percentage of them were satisfied with information from television (46\%), newspapers $(52 \%)$, magazines $(58 \%)$ and the radio $(60 \%)$ [27].

The Internet remains an influential source of information for years after diagnosis, while other sources such as healthcare professionals or books, quickly lose their relevance over time [24]. Probably, the social support provided by the Internet community and the ability to provide up-to-date information contribute to this [2].

What about Internet access to family members? In addition to people with cancer online, an unknown number of friends and relatives of these patients use the Internet. Yakren et al. (2001) have reported that $60 \%$ of patients ${ }^{6}$ friends use the Internet [28]. The fact that many people with cancer are not "direct users" is often neglected. It is their spouses, children or friends who are to search for and retrieve information or communicate via e-mail ("indirect users"). It is estimated that $15 \%$ to $20 \%$ of people with cancer are indirect users $[29,30]$.

G. Eysenbach (2003) identifies four significant uses of the Internet: for communication (e-mail, instant messaging, and voice over IP; for content (health information on the World Wide Web); by the community (newsletters, mailing lists, newsgroups/network usage groups, chats, and community websites); for e-commerce. E-mail could only be useful and profitable for a rather small set of scenarios and conditions that health and social security plans could cover. For other situations, doctors will offer an e-mail as an additional service [2].

Electronic communication can also become an integral part of healthcare services. Hospitals could provide web-based online medical records, thus providing the opportunity for patients to review them, provide additional information or enter the communication module to ask their questions [2].

What is a virtual community? These communities are "social aggregates that appear on the web when enough people hold public discussions for long enough, with enough human sense to form networks for personal relationships in cyberspace" [31]. Alternatively, these may be social networks created or facilitated by the electronic media [32]. In the health context, such groups may be defined as Electronic Support Groups (ESGs).

Most doctors appreciate the availability of health information on the web [19, 33, 34]. According to the majority of oncologists $(95 \%)$, the time spent discussing Internet information has increased in recent years. Nearly half of them admit that sometimes $(38 \%)$, most of the time $(5 \%)$ or all the time $(1 \%)$ had difficulty discussing Internet information. Nine percent have stated that they sometimes or always feel threatened when patients submit Internet information for discussion [19].

The low-quality portion of the network is only one factor in measuring the risk for a user to find poor quality information. Factors such as consumer demand and ability to assess are to be considered [35]. Healthcare professionals, though, can influence all elements. They could publish high-quality information themselves, and educate and train patients how to filter it [2].

Negative results reported in quality assessment studies can be attributed, largely, to the fact that the Internet is a giant market. Much of the information (83\%) is commercial in nature, designed to advertise and sell products and services. Non-profit health information accounts for only $3 \%$ of it. [36]. About 50\% online cancer patients use complementary and alternative medicine $[14,22]$, and $12 \%$ of them use the Internet to buy non-conventional medical therapies online [22].

Today, the effect of the Internet on the outcome of cancer treatment is unclear and may never be fully understood. Therefore, further research is needed to replace purely descriptive studies [2].

\section{E-patients and medical students}

This term, associated with a seemingly new type of patient, an "e-patient", is present in various medical journals, websites, and social media. Although it is tempting to reject the concept as a changing whim, prognoses indicate that e-patients will have a dramatic effect on healthcare systems. Making this impact positive implies that medical teachers become aware of the nature and involvement of e-patients, and how these will influence health care and how to prepare future doctors for e-patients. An 
e-patient is one who seeks medical information on the Internet and makes decisions based on this information [37-40]. In fact, electronic patients are much more numerous. They are thoroughly committed to their health and use a set of online electronic resources in their commitment.

Surveys on Internet use by patients to search for health-related information have shown show that this ranges between 60 and $80 \%$ [41, 42]. The motivation for online search by electronic patients shows that they can sometimes get better information from the Internet than from their doctors. Furthermore, this is more convenient and cheaper, more personal and less embarrassing. It contributes to their treatment and improves the doctor-patient relationship [43-46].

Working constructively with electronic patients is a skill that, like all other skills, has to be taught and learned. The 21 st-century medical curriculum should focus on teaching these skills, and there are indications that medical students are already aware of e-patients and are ready to work with them [47]. While teaching methods in medical schools vary, there are crucial elements that should be taught to all future physicians [48]. These include:

- Basic definitions and statistical data;

- The introductory information mentioned above is a beginning;

- Growth models and Internet use;

- The role of the Internet in the life of patients and its impact on the relationship between patient and doctor;

- Proper use of the Internet by patients;

- Use of e-mail and social media communication (including patient guidance) with patients [49-55];

- Using patient portals $[56,57]$;

- Updating the issues of electronic patients by visiting sites such as http://epatients.net/ and the following Twitter accounts such as@ePatientDave,@ ReginaHolliday, @SusannahFox, @ teaminspire and hashtag \# e-patients.

Physicians (and all healthcare professionals) should be trained to work in this new environment so that the doctor-patient relationship continues to be such as to promote good health.

Medical students should be trained not only how to "talk" and "deal" with electronic patients but also to create working relationships. The latter will teach patients how to contribute to their health. Such training will make sure that the Internet will be used by patients and that it is necessary to ensure that patients will use it correctly and that healthcare professionals can work with available information [58].

The starting point is to teach medical students and other healthcare providers to see an e-patient as a junior colleague who has time and strong motivation (i.e., save their own lives) to find out as much as possible for their medical conditions. Then, just as doctors explain the basics of hygiene and the need for proper drug intake to patients, they need to explain to them how to use the Internet for the benefit of their health.

Medical students will need to be trained, among other things, to understand the mental state of patients, to guide their searches, to advise them on website evaluation, security issues, how to use the information found constructively and how to communicate with their doctors [58].

We cannot know what the health environment will be like in ten years. However, it is evident that will be significant changes. Therefore, physicians and all medical professionals need to be trained how to work in this new environment so that patient-doctor relationships continue to be those that promote good health.

\section{Is e-health progressing faster than e-health researchers are?}

While evidence-based medicine (EBM) is a basic and not the only model of thinking, we should not allow the methodological tools of EBM to guide our thinking. The desire to perform a systematic review and a meta-analysis should not eliminate the differences between intervention and research [59]. When facing such diversity, healthcare consumers are to choose what resources to use. Clinicians prefer EBM quality criteria to support their choice, but these criteria are not applied by the public [60]. Whether we like it or not, online healthcare users prefer untested, amateur products or commercial websites [61]. The impact of this world of abundance results in a competition between health-related information and peer support compete, and this effect is that official Internet communications are competitors, and this has been overlooked in the instructions of Ritterband 
et al. [62].

The International Society for Research on Internet Interventions (ISRII) wants to provide access to the Internet to everyone everywhere. This idea is commendable but being accessible does not mean it will not reach everyone. Online users are not passive recipients: they purchase, try various sources, look at what they have found, and uses services of other online reviews to make their choice [63].

We need an Internet that is not only effective and reliable. We need a net that competes for the attention of health information user and allows people to use multiple sites of their own choice. Among other things, this means that the Internet will have to be free at the point of use, which is not easy to achieve from an economic point of view. H. Potts (2006) predicts that there will be demand for a considerable variety of Internet services that are tailored to the best of their ability [64], just as people usually want personalized health information [61].

Outside of healthcare, the Internet is revolutionary and transformational because it democratizes production and its distribution [63]. Traditional healthcare, considering the safety-critical context, uses a database and risk management process that usually involves some management. These are contradictory trends. The significant advantage of the Internet is the easy access to resources, but safety constraints and evidence of efficacy contradict this.

How do we put together the benefits of the Internet - a democratization of production and distribution that has created so much content, and still maintain safe and good practices? The answer remains unclear, but there is an issue that researcher should consider. Traditional Internet, providing information recommended to patients by healthcare professionals may be only a part of the solution [64]. According to C. Anderson (2008), the value and popularity of user-generated content in the non-health context deserves to be explored and better integrated into online healthcare resources [63]. Chinese hospitals websites, for instance, aim to help hospitals provide quality healthcare regardless of their institutional characteristics, ownership, and rank, and to develop a systematic online marketing and communication strategy. To help patients find information about the hospital, be able to access and understand their medical records [65]. Developing countries are working to improve e-Health services and their adoption across countries [66]. Using the web-based messaging system has given patients an opportunity to receive appropriate advice from their doctors without attending clinics or using the Internet, and $7.3 \%$ of the messages lead to early visits, thus preventing subsequent complications [67].

\section{Conclusions}

Information is often confused with knowledge, and knowledge is, in turn, confused with judgment. Therefore, the challenge for e-learning enthusiasts is to improve the skills of consumers and find the ways to guarantee that these skills become a bridge to doctors. We should keep in mind that the impact depends not only on new technologies. It also relates to our oldest tool human interaction.

Does the Internet influence the outcome of disease treatment? This issue needs to be reformulated. The set-up of the "net effect" is mostly academic because the Internet is an acquisition that society needs. It is far more critical to develop and evaluate platforms that can maximize the positive effect of the Internet, and use the power of information and communication technology for patients who want it.

Interventions on the Internet should be designed to procure a competition in a broader context. The democratization of production and distribution is essential for the effect of the Internet on society. There is a potential contradiction between the need for healthcare and the need for sound evidence and safe practice. This contradiction is a major challenge for online health care that needs to be addressed. In other words, this issue also needs to be legally justified.

\section{Acknowledgements}

This study has no financial support. 


\section{References}

1. NUA. How many online? [Internet]; [cited 2018 Mar 08]. Available from: http://www.nua. ie/surveys/how many online/.

2. Eysenbach G. The impact of the Internet on cancer outcomes. CA Cancer J Clin.2003;53(6):35671.

3. Are online doctors the best medicine? [Internet]. New York: USA Today. c2010. [cited 2018 Mar 08]. New York Office; [about 4 screens]. Available from: https://usatoday30. usatoday.com/yourlife/health/healthcare/ doctorsnurses/2010-11-19-1Ateledoc19_ST_N. $\mathrm{htm}$

4. van Woerkum CM. The Internet and primary care physicians: coping with different expectations. Am. J. Clin. Nutr. 77 (4 Suppl):1016S-1018S.

5. Meyers AD. eMedicine Otolaryngology: an online textbook for ENT specialists. Ear Nose Throat J. 2000;79(4):268-71.

6. Hallam K. Physicians caught in the Web. Thanks to Internet, doc disciplinary data now just a mouse click away. Mod Healthc. 2000;30(37):30-2.

7. Giveon S, Yaphe J, Hekselman I, Mahamid S, Hermoni D. The e-patient: a survey of Israeli primary care physicians' responses to patients' use of online information during the consultation. Isr Med Assoc J. 2009;11(9):53741.

8. Ferguson T, Dreiss M, Fox S, Frydman G, Graedon J, Graedon T, et al. e-Patients: How they can help us help health care. San Francisco; 2007.

9. Masters, K. Opening the non-open access medical journals: Internet-based sharing of journal articles on a medical web site. Int J Med Inform. 2008;5(1):[about 6.]. Available from: http://ispub.com/IJMI/5/1/6971

10. Masters, K. Articles shared on a medical web site - an international survey of non-open access journal editors. Int J Med Inform. 2010;5(2):[ about 6 p]. Available from: https://print.ispub. com/api/0/ispub-article/13669.

11. Marshall WW, Haley RW. Use of a secure Internet Web site for collaborative medical research. JAMA. 2000;284(14):1843-9.

12. Baker L, Wagner TH, Singer S, Bundorf MK. Use of the Internet and e-mail for health care information: results from a national survey. JAMA 2003;289(18):2400-6.

13. Fox S. The Online health care revolution: how the Web helps Americans take better care of themselves. Washington:The Pew Internet and American Life Project;.2000.
14. Pereira JL, Koski S, Hanson J, Bruera ED, Mackey JR. Internet usage among women with breast cancer: an exploratory study. Clin Breast Cancer. 2000;1(2):148-53.

15. Norum J. Evaluation of Norwegian cancer hospitals 'Web sites and explorative survey among cancer patients on their use of the Internet. J Med Internet Res. 2001;3(4):e30.

16. Norum J, Grev A, Moen MA, Balteskard L, Holthe K. Information and communication technology in oncology. Patients' and relatives' experiences and suggestions. Support Care Cancer. 2003;11(5):286-93.

17. Mills ME, Davidson R. Cancer patients' sources of information: use and quality issues. Psychooncology. 2002;11(5):371-8.

18. Oncologists disagree on impact of patient Internet use. CA Cancer J Clin. 2003;53(3):1357.

19. Helft PR, Hlubocky F, Daugherty CK. American oncologists' views of Internet use by cancer patients: a mail survey of American Society of Clinical Oncology members. J Clin Oncol. 2003;21(5):942-7.

20. Irving L, Klegar-Levy $\mathrm{K}$, McConnaughey J, Everette DW, Reynolds T, Lader W. Falling through the net: Defining the digital divide. A report on the telecommunications and information technology gap in America. Washington: National Telecommunications and Information Administration;1999.

21. Brodie M, Flournoy RE, Altman DE, Blendon RJ, Benson JM, Rosenbaum MD. Health information, the Internet, and the digital divide. Health Aff (Millwood) 2000;19(6):255-65.

22. Metz JM, Devine P, DeNittis A, Hampshire M, Godwein J, Whittington R. A multi-institutional study of Internet utilization by radiation oncology patients. Int J Radiat Oncol Biol Phys. 2003;56(4):1201-5.

23. Smith RP, Devine P, Jones H, DeNittis, A., Whittington, R. Metz, JM. Internet use by patients with prostate cancer undergoing radiotherapy. Urology. 2003;62(2):273-7.

24. Satterlund MJ, McCaul KD, Sandgren AK. Information gathering over time by breast cancer patients. J Med Internet Res 2003;5(3):e15.

25. Peterson MW, Fretz PC. Patient use of the Internet for information in a lung cancer clinic. Chest. 2003;123(2):452-7.

26. Diefenbach MA, Dorsey J, Uzzo RG, Hanks GE, Greenberg RE, Horwitz E, et al al. Decision-making strategies for patients with localized prostate cancer. Semin Urol Oncol. 2002;20(1):55-62.

27. Raupach JC, Hiller JE. Information and support for women following the primary treatment of 
breast cancer. Health Expect. 2002;5(4):289301.

28. Yakren S, Shi W, Thaler H, Agre P, Bach PB, Schrag D, et al. Use of the Internet and other information resources among adult cancer patients and their companions. Proc Am Soc Clin Oncol. 2001;20:398a.

29. Vordermark D, Kölbl O, Flentje M. The Internet as a source of medical information. Investigation in a mixed cohort of radiotherapy patients. Strahlenther Onkol 2000;176(11):532-5.

30. Fleisher J. Relationships among Internet health information use, patient behavior and selfefficacy in newly diagnosed cancer patients who contact the National Cancer Institute's Atlantic Region Cancer Information Service. Proc AMIA Annual Symp.2002:260-4.

31. Rheingold H. The virtual community. London: Addison-Wesley; 1993.

32. Wellman B. An electronic group is virtually a social network. Kiesler S, editor. Cultures of the Internet. Mahwah: Lawrence Erlbaum; 1997.

33. Chen X, Siu LL. Impact of the media and the Internet on oncology: survey of cancer patients and oncologists in Canada. J Clin Oncol. 200;19(23):4291-7.

34. Murray E, Lo B, Pollack L, Donelan K, Catania $\mathrm{J}$, Lee K,et al. The impact of health information on the Internet on health care and the physicianpatient relationship: National U.S. survey among 1.050 U.S. physicians. J Med Internet Res 2003;5(3):e17.

35. Eysenbach G, Powell J, Kuss O, Sa ER. Empirical studies assessing the quality of health information for consumers on the World Wide Web: a systematic review. JAMA 2002;287(20):2691-2700.

36. Lawrence S, Giles CL. Accessibility of information on the Web. Nature. 1999;400(6740):107-9.

37. Podichetty VK, Booher J, Whitfield M, Biscup RS. Assessment of Internet use and effects among healthcare professionals: a cross sectional survey. Postgrad Med J. 2006;82(966):274-9.

38. Ferguson T. E-Patient Scholars Working Group. 2007. E-patients: how they can help us heal healthcare. Patient advocacy for health care quality. Strategies for achieving patientcentered care. Canada: Jones and Bartley;2008, p. 93-121.

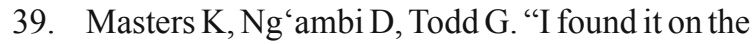
Internet": preparing for the e-patient in Oman. Sultan Qaboos Univ Med J. 2010;10(2):169-79.

40. Fraval A, Chong YM, Holcdorf D, Plunkett V, Tran P. Internet use by orthopaedic outpatients - current trends and practices. Australas Med J. 2012;5(12):633-8.
41. Colineau N, Paris C. Talking about your health to strangers: understanding the use of online social networks by patients. New review of hypermedia and multimedia. 2010;16(1-2):14160.

42. Fox S, Duggan M. Health online. Washington: Pew Research Center; 2013.

43. Diaz JA, Griffith RA, Ng JJ, Reinert SE, Friedmann PD, Moulton AW. Patients' use of the Internet for medical information. J Gen Intern Med. 2002;17(3):180-5.

44. Fox S. E-patients with a disability or chronic disease. October 8;2007; Washington: Pew Research Center;2007.

45. Hay MC, Cadigan RJ, Khanna D, Strathmann C, Lieber E, Altman R, et al. Prepared patients: Internet information seeking by new rheumatology patients. Arthritis Rheum. 2008;59(4):575-82.

46. Klinar I, Balazin A, Baršić B, Tiljak H. Identification of general characteristics, motivation, and satisfaction of internet-based medical consultation service users in Croatia. Croat Med J. 2011;52(4):557-65.

47. Harper L, Brock SM. The eventuality of the e-patient. Med Teach. 2016;38(6):635.

48. Masters K. Preparing medical students for the e-patient. Med Teach. 2017;39(7):681-5.

49. Bovi AM. 2003. Ethical guidelines for use of electronic mail between patients and physicians. Am J Bioeth..2003;3(3):W-IF2.

50. Thompson LA, Dawson K, Ferdig R, Black EW, Boyer J, Coutts J, et all. The intersection of online social networking with medical professionalism. J Gen Intern Med. 2008;23(7):954-7.

51. Jain SH. Practicing medicine in the age of Facebook. N Engl J Med. 2009;361(7):649-51.

52. Garner J, O'Sullivan H. Facebook and the professional behaviors of undergraduate medical students. Clin Teach. 2010;7(2):112-5.

53. Gray K, Annabell L, Kennedy G. Medical students" use of Facebook to support learning: insights from four case studies. Med Teach. 2010;32(12):971-6.

54. Bosslet GT, Torke AM, Hickman SE, Terry CL, Helft PR. The patient-doctor relationship and online social networks: results of a national survey. J Gen Intern Med. 2011;26(10):1168-74.

55. Televox. Technology beyond the exam room: How digital media is helping doctors deliver the highest level of care [Internet]. 2012: [cited 2018 Mar 08]; [about 31 p.]. Available from: https:// www.televox.com/downloads/technology

56. Shachak A, Jadad A. Electronic health records in the age of social networks and global telecommunications. JAMA. 2010;303(5):4523 . 
57. Dalal AK, Schnipper J, Massaro A, Hanna J, Mlaver E, McNally K, et al. A web-based and mobile patient-centered "microblog" messaging platform to improve care team communication in acute care. J Am Med Inform Assoc. 2017;24(e1):e178-e184.

58. Masters K. The e-patient and medical students. Med Teach. 2016;38(3):314-6.

59. Eysenbach G, Kummervold PE. "Is cybermedicine killing you?" - the story of a Cochrane disaster. J Med Internet Res. 2005;7(2):e21; doi: 10.2196/jmir.7.2.e21.

60. Marshall LA, Williams D. Health information: does quality count for the consumer?: How consumers evaluate the quality of health information materials across a variety of media. Journal of Librarianship and Information Science. 2006;38(3):141-56.

61. Sillence E, Briggs P, Harris P, Fishwick L. Changes in online health usage over the last 5 years. Proceeding. of the Conference of human factors in computing systems; 2002 Apr 22-27; Montreal, Canada. 2006. p. 1331-6.
62. Ritterband LM, Andersson G, Christensen HM, Carlbring P, Cuijpers P. Directions for the International society for research on Internet interventions. J Med Internet Res. 2006;8(3):e23.

63. Anderson $\mathrm{C}$. The long tail: why the future of business is selling less of more. $1^{\text {st }}$ ed. New York: Hyperion; 2008.

64. Potts HWW. Is e-health progressing faster than e-health researchers? J Med Internet Res. 2006;8(3):e24. doi:10.2196/jmir.8.3.e24.

65. Huang E, Wang J, Liu T. Interactive e-health tools for patients on Chinese hospitals' websites. Int J Healthc Manag. 2014;7(2):75-83.

66. Hoque MR, Bao Y, Sorwar G. Investigating factors influencing the adoption of e-Health in developing countries: a patient's perspective. Inform Health Soc Care. 2017;42(1):1-17.

67. Jeong da E, Kim KO, Jang BI, Kim EY, Jung JT, Jeon SW, et al. The clinical usefulness of a webbased messaging system between patients with Crohn disease and their physicians. Medicine (Baltimore). 2016; 95(26):e4028. 